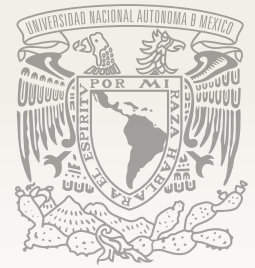

\title{
Revista
}

Pueblos y fronteras

\section{LA IMPORTANCIA DEL CUERPO EN LA NOCIÓN DE PERSONA ENTRE MAYAS ACTUALES DE OXCHUC, CHAMULA Y CHENALHÓ, CHIAPAS}

Jaime Tomás Page Pliego

jaimepagepliego@gmail.com

PROIMMSE-IIA-UNAM

\section{RESUMEN}

Suele asumirse que la noción de persona es igual entre los pueblos de tsotsiles y tesltales de los Altos de Chiapas. Sin embargo, su configuración varía sustancialmente, sin perder la base que los une. Este trabajo trata sobre las diferencias y similitudes que se presentan en el concepto denominado complejo persona en tres municipios: Oxchuc — de habla tseltal—, Chamula y Chenalhó — de habla tsotsil—, y en forma destacada sobre la importancia del cuerpo en dicho concepto. Asimismo, se abordan las variaciones que se han suscitado en torno a esa noción a partir de 1940, bajo la incidencia de la escalada proselitista cristiana.

Palabras clave: noción de persona, diferencias y similitudes, transfiguración.

\section{THE IMPORTANCE OF THE BODY WITHIN THE COMPLEX OF THE NOTION OF PERSONHOOD AMONG CONTEMPORARY MAYANS FROM OXCHUC, CHAMULA AND CHENALHÓ IN CHIAPAS STATE}

\section{ABSTRACT}

There is a tendency to assume that the Tsotsil and Tseltal communities in the Chiapas Highlands (Altos de Chiapas) share the same notion of personhood. However, the way this notion is constructed does vary substantially without losing a common foundation. This piece of research deals with the similarities and differences present in the concept of personhood complex in three different municipalities: Oxchuc —a tseltal-speaking community—, Chamula and Chenalhó - tsotsil-speaking communities-, and emphasizes the importance of the body in this concept. It also addresses the permutations that have emerged around this notion since 1940, under the escalating influence of Christian proselytism.

Key words: personhood, differences and similarities, transfiguration. 


\section{INTRODUCCIÓN}

En este trabajo me aproximo a la noción de persona a partir de lo que Bartolomé (1991: 143155) designa como persona espiritual. Se refiere a «construcciones ideológicas fundamentales para la construcción del individuo», en alusión específica a las diferentes entidades anímicas. Desde esta perspectiva, el acercamiento a la noción de persona entre los tradicionalistas tseltales de Oxchuc y los tsotsiles de Chamula y Chenalhó ${ }^{1}$ no soslaya las otras consideraciones sobre la persona (social, política, jurídica). Sin embargo, constituye el marco que permite visualizar integralmente la noción en todas sus acepciones, así como su interrelación.

Lo anterior coadyuva de manera determinante a la posibilidad de delinear cómo las sociedades se conciben y cómo se viven los individuos como personas y se insertan en una dinámica sociocultural particular.

Como producto histórico, la noción de persona en Mesoamérica ha ido variando a lo largo del tiempo y ajustándose de distintas maneras al flujo diferenciado de las dinámicas sociales en cuyo devenir se han suscitado condiciones que, aunadas a elementos muy resistentes al cambio «pero no inmune [s] a este» (López-Austin 1996: 26 y Meslin 1978: 231), presentes en la cosmovisión, han permitido su transfiguración sin llevarla a perder su esencia.

Considero, entonces, que las diferencias documentadas en relación con la cosmovisión, la etnomedicina y, en forma concomitante, la noción de persona son resultado del devenir particular de cada municipio, con mención especial de los sucesos de los últimos 50 años.

\section{ANTECEDENTES}

Tal como señala Alessandro Lupo (1999: 23), entre los grupos que han habitado Mesoamérica desde antes de la llegada de los españoles, la noción de persona se ha concebido y estructura-

\footnotetext{
${ }^{1}$ El término tradicionalista ha sido adoptado por pedranos y chamulas para distinguirse de católicos y protestantes, y se definen como quienes viven y dan continuidad a las costumbres y la religión legada por sus antepasados. En este sentido es utilizado en el presente trabajo.
}

do de maneras muy diferentes respecto de los conceptos de la sociedad que los coloniza y los domina.

Las disímiles formas en que se configura dicha noción en la actualidad entre los pueblos originarios de la región remite, entre otros factores, a la multiplicidad de relaciones que las poblaciones a lo largo de tiempo han establecido con la biodiversidad y la tierra, formas de organización social, relaciones diferenciadas con el colonialismo y neocolonialismo civil y religioso, etcétera.

Estos elementos los destaca López-Austin (1992: 28) cuando se refiere a que el «complejo religioso mesoamericano» se caracterizó por la confluencia de diversas sociedades, con distinto grado de desarrollo e interacción diferenciada en los campos económico, político, religioso y de dominación-subordinación, todo lo cual coadyuvó a matizar los ámbitos de lo mítico, lo religioso y, en términos más amplios, el de la cosmovisión, "como un conjunto estructurado de procesos sociales, creencias, prácticas, valores y representaciones que se van transformando a lo largo de los siglos».

La noción de persona espiritual en Mesoamérica se caracteriza en general por la presencia y confluencia de diversas entidades anímicas, algunas de naturaleza sutil, como el ch'ulel entre los mayas de los Altos de Chiapas o la sombra entre nahuas, noción presente en todo lo que ha sido Mesoamérica; o entre los nahuas proyecciones de diferentes órganos, si no animales compañeros que habitan fuera o dentro de los individuos, o fenómenos naturales como entre los mayas. Además de la capacidad mesoamericana de algunos pocos individuos de transmutarse en otro ente o bien de imponer su voluntad en otros seres o fenómenos de la naturaleza. Complejo tan variable como pueblos hay, en cuya multiplicidad es posible encontrar ese hilo que aún hoy nos permite hablar de la persistencia del complejo religioso mesoamericano.

La noción de persona entre los tsotsiles de Chamula y Chenalhó, así como entre los tseltales tradicionalistas y católicos de Oxchuc (véase mapa), aun con la influencia de elementos religiosos de nuevo cuño — aunque ya se pierde, más en Oxchuc - todavía se conforma estrechamente vinculada al reino animal y a fenómenos 
naturales, razón por la cual en estos pueblos no remite exclusivamente al cuerpo, sino que es elocuente respecto de la multiplicidad de entidades que la conforman, de las cuales la mayoría se moviliza preferentemente en el espacio onírico. En este sentido, Le Breton (2006: 22) hace alusión a la tendencia del hombre a confundirse «con el cosmos, la naturaleza, la comunidad».

De los primeros trabajos que indagan sobre particularidades, especificidades y diferencias sobre la noción de persona entre los mayas de los Altos de Chiapas tenemos los publicados en español en las décadas de 1960-1970, que refieren a reportes de estudios realizados con un solo informante, como el de Holland (1963), quien presenta las particularidades de la persona desde una perspectiva etnomédica en lo que en la actualidad se denomina San Andrés Sacamch'en; Guiteras (1965), a partir de una amplia etnografía respec- to de San Pedro Ch'enalhó; Vogt (1980), quien trabajó exhaustivamente Zinacantán; Hermitte (1970), en Pinola, hoy Las Rosas; Gossen (1975), Pozas (1977) y Arias (1975), que reportaron sobre Chamula; y Köhler (1995), cuyo trabajo más significativo fue realizado en San Pablo Chalchihitán. En tanto que para Oxchuc destacan los trabajos de (Harman (1990) y Siverts (1969).

Después de más de tres décadas de silencio, a partir de la década de 1990 resurge el interés por esta temática. De entre las publicaciones recientes destacan las de los siguientes autores: Pitarch (1996), para Cancuc; Page (2010 y 2011 [2005]), quien ha reportado sobre Chamula, Ch'enalhó y Oxchuc; Sánchez (2007) que ha escrito sobre los tseltales de Yajalón; López (2007) y Diesmo (2012), antropólogos chamulas que han realizado trabajos de relevancia sobre sus comunidades de origen.

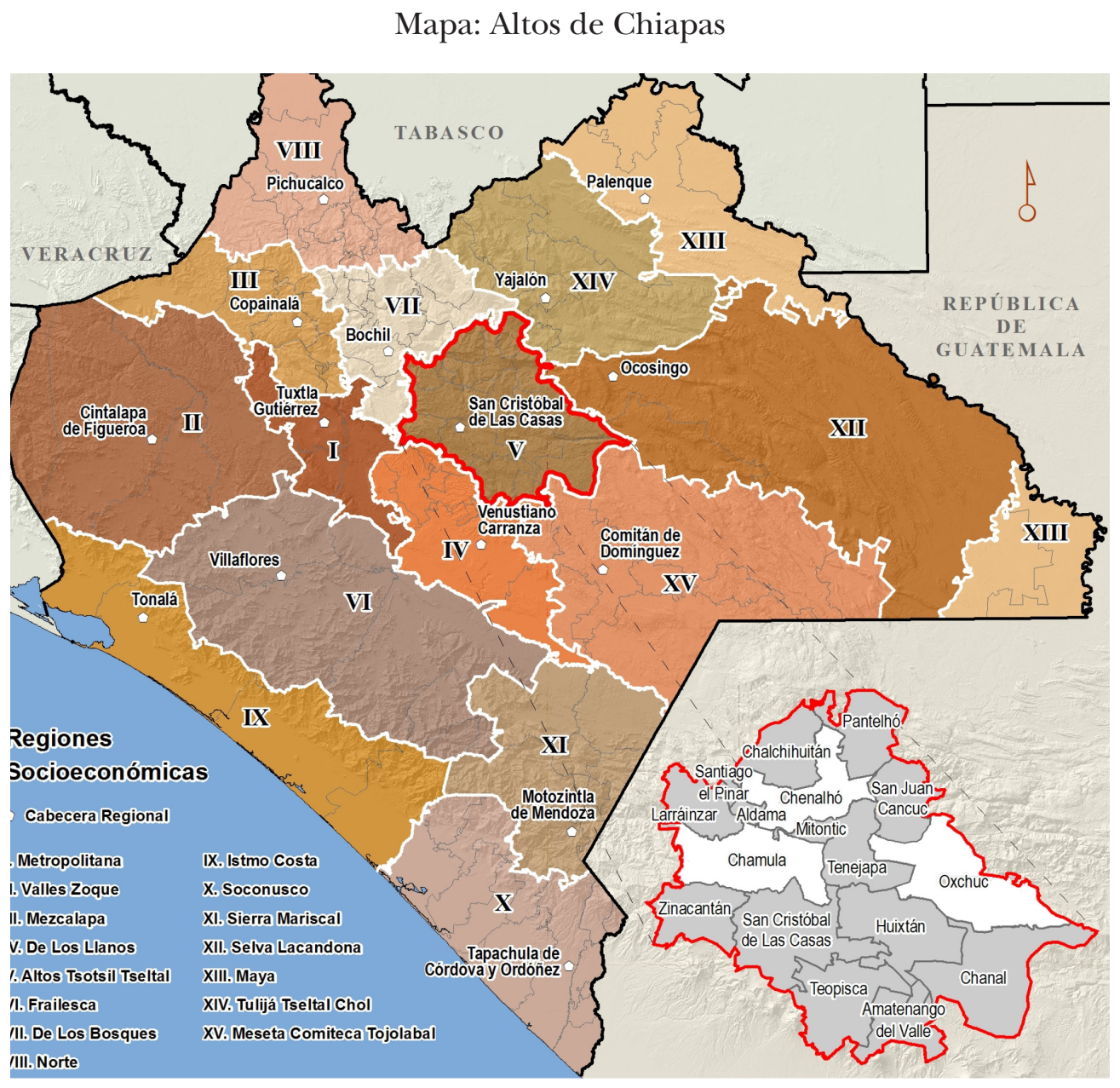

Fuente: Comité Estatal de Información Estadística y Geográfica de Chiapas http:/ /www.ceieg.chiapas.gob.mx/home/mapas-regionales/ 
En los trabajos señalados resalta la complejidad y diversidad de la noción de persona entre los mayas de los Altos de Chiapas. En sus distintas conformaciones nos encontramos con matices distintivos y varios elementos comunes: cuerpo humano, ch'ulel-alma, vela de la vida y lab —-tseltales- o quibal —-tsotsiles-; esta última entidad corresponde a la capacidad, con particularidades diferenciadas de transformación a voluntad en animales, humanoides, fenómenos meteóricos, naturales o sobrenaturales, inherente a contados miembros de estas sociedades.

Respecto del álter ego o animal compañero (vayijelil o chanul), cuya presencia entre chamulas y pedranos (Page 2011) desempeña un papel decisivo en la persona que se es y su devenir. Cabe señalar que no es parte de la persona entre los tseltales de Oxchuc (Page 2010), pero sí entre los de Yajalón (Sánchez 2007) y Cancuc (Pitarch 1996).

\section{PROCESOS SOCIOHISTÓRICOS Y ECONÓMICOS DIFERENCIADOS}

Las marcadas diferencias que podremos observar en las dinámicas socioculturales, religiosas y de organización social entre los tseltales de Oxchuc con tsotsiles de Chamula y Chenalhó solo se pueden explicar en parte, pero de manera importante, a la luz de los procesos sociohistóricos y económicos diferenciados que han tenido lugar en cada municipio, sobre todo a partir de la década de 1940.

Destacan, para uno y otro municipio, formas distintas de inserción y relación con la sociedad ladina y el Estado mexicano, así como una respuesta diferenciada ante el embate de los grupos de corte calvinista que iniciaron sus actividades en dicha época y que desde mi punto de vista han sido determinantes en los innumerables cambios y transfiguraciones que han tenido lugar en estos pueblos.

Los casos de Chamula y Oxchuc tienen en común la pobreza, que deriva de la improductividad de la tierra, lo que los condenó a constituirse en reserva de mano de obra para las grandes fincas de tierra caliente. Sin embargo, su relación con la sociedad mexicana ha transcurrido por derroteros distintos.
Los chamulas, a pesar de la cercanía con San Cristóbal de Las Casas $(9 \mathrm{~km})$ pudieron mantener en sus manos el gobierno y, tal vez por dicha cercanía, una estructura religiosa consolidada y poderosa, lo que les permitió autonomía relativa respecto de la sociedad nacional. Esto prevalece hasta la fecha.

En esta sociedad, hasta hace una década el poder religioso fue preponderante en la resolución de la conflictividad social y factor fundamental para resistir y neutralizar durante largo tiempo el embate protestante y católico (Page 2011).

Respecto de Oxchuc, a excepción de la contratación de fuerza de trabajo para las fincas, este municipio recibió escasa atención civil y religiosa desde la colonia hasta la década de 1930.

Como resultado de la política colonial de reparto en que los parajes de la región fueron conformados con familias de diferente procedencia, y se desarticuló de ese modo parte importante de sus culturas, saberes y aspectos de orden religioso, aunado, particularmente en Oxchuc, a la escasa atención que la iglesia católica brindó a la población del municipio, dio por resultado una estructura religiosa endeble, por no decir que ausente, en que la dinámica sobrenatural y de control social se centró en el riesgo de sufrir el infortunio del ak-chamel 'mal echado' como consecuencia de no satisfacer los caprichos de los ancianos cabeza de linaje, personajes cuyas personas detentaban poderosos lab a través de los que producían daño a discreción (Villa 1990: 530).

En la década de 1930 se crearon los primeros asentamientos ladinos, ${ }^{1}$ siendo su presencia corta, ya que tres décadas después fueron expulsados del municipio (Harman 1990, Moguel y Parra 1998, Page 2011: 19).

La permanencia de ladinos en Oxchuc terminó en la década de 1970, debido a que sus fuentes de ingreso, como la venta de pox, fueron cortadas y recuperados los predios que gra-

\footnotetext{
${ }^{1}$ Distingo entre mestizos y ladinos de la siguiente manera: mestizos son aquellas personas que llevan sangre española e indígena pero que no viven en contacto cotidiano con población originaria, como es la mayoría de la población mexicana; ladinos son aquellos mestizos que viven en regiones donde predomina la población originaria, con la que interactúan cotidianamente.
} 
dualmente se fueron adjudicando mediante el despojo a la población tseltal (Moguel y Parra 1998, Page 2010).

En lo que toca al rápido cambio de adscripción religiosa hacia el protestantismo y menos al catolicismo, lo adjudicamos a la frágil religiosidad ya referida, y al terror de la población a sufrir de ak'chamel, hechos que facilitaron el éxito del embate emprendido por diversas iglesias cristianas, que en el término de cinco años de trabajo intensivo lograron aproximadamente la conversión de la mitad de la población, lo que resulta un hecho sin precedentes en el acontecer sobre la temática religiosa (Siverts 1969: 175).

Chenalhó, el tercer municipio, se caracterizó, debido a la riqueza de sus tierras, por la presencia temprana de población mestiza; mantuvo el control político, económico y religioso hasta la década de 1930, y el poder religioso quedó en este caso subordinado al político, sin incidir de manera importante en las formas religiosas tradicionales de la población tsotsil.

Dicha forma de organización social y religiosa coadyuvó a que la conflictividad social se resolviera en el ámbito de lo civil, conforme a la «legalidad nacional» (Page 2011).

Por otro lado, sin menoscabo de la subordinación, a diferencia de Oxchuc la acción católica emprendida desde la colonia y que llega hasta nuestros días, ha sido intensa en la cabecera municipal y desde 1970, mediante la acción católica de los comités eclesiales de base, se extendió a todo el municipio.

Los elementos señalados han marcado una dinámica más de lograr consensos que de ahondar conflictos con los grupos protestantes, dando lugar a que en el seno del tradicionalismo pedrano (san Pedro es el patrón de Chenalhó) se hayan gestado, más que en Chamula, la mayor parte de las transfiguraciones que se han suscitado en la cosmovisión, la religiosidad tradicionalista, el sistema etnomédico y, por tanto, en la noción de persona. Aunque en este municipio han predominado dichas transfiguraciones, los procesos han incidido de manera determinante en Chamula como consecuencia del intenso intercambio en todos los planos que tiene lugar entre ambos pueblos.
En síntesis, podemos vislumbrar que la posibilidad de chamulas y pedranos de sostener y perpetuar sus formas de concebir y de vivir el mundo llevan a una conformación de la persona y del cuerpo mucho más ligada a la religiosidad tradicional. En tanto que los oxchuqueros se inclinan hacia la visión judeocristiana occidental de la persona y centran sus conceptos en aspectos propios de la naturaleza.

\section{LA CONFORMACIÓN DE LA PERSONA}

Hemos encontrado que tanto entre los tseltales de Oxchuc (Page 2010: 90) como entre los de Yajalón (Sánchez 2007: 22) se considera que todo sujeto al nacer trae un majtanil, lo que hace referencia a un regalo especial que Dios concede. Dicho don se guarda en secreto en el seno familiar, es cosa sagrada e innombrable.

Desde el embarazo las chichiletik 'parteras' empiezan a percibir elementos que apuntan a delimitar el tipo de persona que será el nonato. Esa visión se refuerza durante el trabajo de parto. Sin embargo, es mediante el majtanil que se llega a la certeza sobre el recién nacido dentro de la taxonomía del grupo social del que forma parte (entre otras: 'poderosa', 'fuerte', 'normal' y 'débil'. Véase Page 2011). Esto se define a partir de los chanul alal 'adornos presentes en el cuerpo al nacer', que aparecen en la pojtsil 'placenta' o 'envoltura' y, especialmente, las señales en forma de collar que se presentan en el ch'ujt 'cordón umbilical'.

Dichas señales le permiten a la chichilvaticinar con alguna certeza respecto del tipo de ch'ulel-alma y yu'el 'poder' de que viene dotado el recién nacido y con ello pronosticar sobre las cualidades físicas que como persona tendrá y que se reflejarán en el vigor corporal, la inteligencia, la estabilidad emocional, etc., así como en las cualidades morales y la fortaleza espiritual.

Se afirma que solo los padres deben conocer el majtanily su significado, es decir, la personalidad y las artes de que el vástago ha sido dotado, si será buena o mala persona.

Entre los tseltales de Oxchuc el majtanil remite además a algún fenómeno u objeto de la naturaleza del que toda la persona, incluido el ch'ulel, adquirirá los atributos, mismo que será 
revelado a alguno de los progenitores a través de un sueño que tiene lugar el día en que se produce la fecundación, elemento que también dará indicios sobre el sexo de la criatura.

$\mathrm{Al}$ respecto, sobre el tipo de majtanil hay distinciones entre los que corresponden a mujeres o a hombres: la mujer puede estar ligada a jícara, taza, bule, arete, gallina, todo lo relativo al sexo femenino, estrella fugaz, arcoíris, lluvia, zorrillo. El hombre aparece ligado, entre otros, al hacha, rayo, torbellino, pedernal, machete, coa, viento, jaguar y puma (Page 2010: 91).

En lo que toca a yu'el 'fuerza', 'poder', noción que remite no solo a la fortaleza física sino también al poder sobrenatural, las opiniones en Oxchuc son variadas respecto a su intensidad a lo largo de la vida. Como en todos los Altos de Chiapas, quienes mayor poder alcanzan por predestinación son quienes ayudan a sanar (poxtawanejetik).

En torno al incremento o mengua de yu'el a lo largo de la vida se documentaron dos posiciones. Por un lado, se señala que va menguando conforme se envejece:

Hay un viejito que hace un año se murió por un ataque, que ya no tuvo valor de salvarse, dicen que cuando él era joven fue el mejor. [...] Cuando se envejeció ya no podía sanar a sus enfermos. Por esto los viejitos de la que saben curar siempre tiene que acabar su yu'el o su suerte que traen cada uno de ellos, eso es lo que he visto a mi parte (entrevista a don Faustino López, p. 16).

Por otro lado, hay quienes sostienen que el yu'el más bien se incrementa:

Por ejemplo, cuando los encuentras en el camino [a los ancianos] y primero te hablan, si ven que tú no contestas, que solo vienes chiflando como pájaro, es falta de respeto para él. Así que cuando llega a su casa empieza a hablar de ti y con eso te viene la enfermedad. Porque todo lo que dice el viejito, el Diablo lo está escuchando. Por eso el Diablo es testigo de lo que hacemos. Por eso cuando te enfermas no te puedes curar así nomás con la medicina, sino hasta que te vas con un ch'abajel. Allí te dicen que le faltaste el respeto a tal mamtik.

Allí es donde llegamos a saber que ese mamtik es muy fuerte, que no podemos decirle nada y allí lo empezamos a respetar porque ya nos demostró que tiene yu'el. Por eso dicen que son muy fuertes y pueden dominar nuestras almas y mandarnos enfermedad (entrevista a doña Florentina López, p. 14).

Lo antedicho se refleja en el miedo que las personas tienen a los ancianos, y que fue la causa del asesinato de los k'atinab 'autoridad religiosa más importante' entre 1900 y 1920 (Favre 1973: 249-250) y los asesinatos de ancianos que señala Harman (1990: 28-29) hacia finales de la década de 1930 y principios de la siguiente.

Por otro lado, entre los tsotsiles de Chamula y Chenalhó que nos han acompañado se sostiene que las horas, los días, la posición lunar y factores de orden sobrenatural adquieren gran importancia no solo en las características que tendrá la persona sino también en el tipo de cuerpo, su constitución y fortaleza, así como en los atributos del carácter. Entre los factores más comunes, pero de mayor importancia, se encuentran los siguientes:

Si se nace como a las seis de la mañana, hora en que el «Lucero» - astro verde ligado a las deidades celestiales- está en el Cielo, el recién nacido tendrá buena suerte, será inteligente y trabajador. A este astro en San Andrés se le denominaba Muc'ta chon 'Gran Serpiente' (Holland 1963: 77).

Cuando una estrella que destaca en brillo por sobre las demás (no se especifica cuál) se encuentra en el cenit, Xolom c'on y una persona nace en ese momento, su vida durará la mitad de lo que duraría si este hecho no se hubiera presentado.

La llamada estrella de «zapato» situada en posición de zapatos nuevos (no se nos precisó su ubicación celeste) pronostica que la persona que nació bajo su influjo será asesinada; y por el contrario, cuando se nace en lo que se denomina «zapatos viejos», se tendrá buena suerte, vida larga y fuerza.

Cuando alguien nace al mismo tiempo que una estrella (estrella fugaz), esa persona tendrá siempre dos o tres compañeros sexuales o cambiará de pareja frecuentemente.

En relación con la luna (asociada con la Virgen) se dice que cuando la persona nace durante la fase de luna llena «maciza» vivirá durante mucho tiempo, su dentadura será fuerte, 
sus dientes nunca se quebrarán y sus muelas no se picarán; será una persona fuerte y trabajadora; aprenderá a caminar como a los siete u ocho meses. En algunos lugares, cuando alguien nace bajo este sino, los padres hacen una fiesta para celebrar el acontecimiento y la buena suerte. ${ }^{2}$

Por otro lado, se mencionan circunstancias que apuntan hacia una mala constitución física, o mal sino. Por ejemplo, cuando la luna tiene un matiz rojizo durante su plenitud, muchas mujeres de edad media y avanzada mueren por no haberle tributado. El color rojizo es atribuido a lágrimas que la Luna-Virgen derrama debido a que la entristece no poder evitar que las mujeres que descuidaron sus ofrendas mueran.

Cuando se nace en luna tierna o a la mitad, la persona será débil, envejecerá demasiado pronto y seguramente no vivirá mucho; sus huesos serán frágiles, además será una persona «calmuda».

Entre los fenómenos más temidos se encuentran los eclipses de sol y de luna. Cuando la vista del sol «se apaga» se le denomina Stub sat j'totic, cuando sucede con la luna, Stub xchab j'metic. Se piensa que el eclipse de luna tiene lugar cuando la luna es golpeada y sangra, por ello su resplandor se oculta y muere. En ninguna de las dos circunstancias las mujeres embarazadas deben mirar hacia el cielo, es más, deben permanecer confinadas en sus casas, porque los enemigos están ahí. Si no lo hacen, sus hijos nacerán incompletos: sin labios (labio leporino), sin una mano o brazo, sin piernas, solo pies.

Si se nace durante un eclipse inevitablemente se sufrirá la falta de alguna parte del cuerpo, por lo que a las parturientas se les recomienda que retengan la culminación del parto hasta que el eclipse haya terminado.

En lo que respecta a la influencia de las horas del día, los conceptos son diferentes y por momentos hasta contradictorios. En general se dice que si se nace por la tarde la persona será longeva; si muy temprano, al amanecer, crecerá débil, de huesos frágiles, enfermiza y no vivirá mucho

\footnotetext{
${ }^{2}$ En los Altos de Chiapas existe la práctica, incluso entre los mestizos, de realizar el corte de los árboles durante la fase de luna llena, toda vez que de esta manera, según se dice, nunca se pudre y en las estructuras de la casas permanece más del siglo.
}

tiempo. Quienes nacen al mediodía envejecen prematuramente. En contraposición, algunos de los colaboradores dicen que cuando el sol ya está macizo, por la tarde como a la una o dos, entonces la persona vivirá muchos años. Afortunadamente, la mayoría de los niños nacen alrededor de la medianoche y pocos durante el día, por eso solo algunos están sujetos a este posible mal sino.

Otra circunstancia adversa es la de nacer mientras los perros se están apareando o cuando están en celo, dado que ello implica que «[...] allí están los brujos» y el resultado esperado es que esa persona será un «hombre o mujer de la calle», que estará siempre buscando sexo.

Si se nace con el cordón umbilical alrededor del cuello, se morirá de muerte violenta. Este destino se evita si la partera recomienda con Dios al recién nacido, los Anjeletik, la Madre Tierra, Vírgenes, Apóstoles y Santos. Otro secreto para evitar este sino maligno es cortar el cordón en tres pedazos y enterrarlo, «así el enemigo no puede ganar».

El secreto para neutralizar toda influencia que pueda tener alguna repercusión en la fortaleza, salud o buen actuar de la persona, parte de que la j'tamul 'partera' o el j-ilol lleven a cabo rituales secretos que generalmente desembocan en encomendar y pedir a las deidades, de la manera apropiada según el caso, que corrijan el mal que ha caído sobre la criatura.

Los factores que se considera determinan las características que tendrá la persona entre Oxchuc y los tsotsiles de Chamula y Chenalhó es diferente: El oxchuquero se centra en las características del parto, la placenta y el cordón umbilical; es decir, en elementos de orden físico, para entrever el sino y la estructura de la persona, en tanto que entre los tsotsiles prevalece la asociación con los fenómenos naturales y el movimiento de las fuerzas sobrenaturales.

En ambos casos, si se es una persona común y corriente, se requiere rogar frecuentemente a las deidades por protección y salud mediante la realización de rituales y entrega frecuente de ofrendas, en tanto que si se es un «hijo de Dios» al que le han sido entregadas promesas y entidades anímicas poderosas ${ }^{3}$ no se requieren tantos

\footnotetext{
${ }^{3}$ Que Villa (1990: 133) situó como: «Las bases cosmológicas de la autoridad tradicional».
} 
cuidados, pero deberá dedicar su persona a servir a los demás en la eterna batalla contra el mal, la enfermedad y la muerte.

En el caso de los tsotsiles, al situar Dios permanentemente a la persona en el umbral de la salud-enfermedad-muerte, suma una razón más para obligarle a proporcionar manutención a las deidades celestiales, el alimento que requieren y que así aseguran.

\section{LA LLEGADA DEL CH'ULEL-ALMA ${ }^{4}$}

Dado que las representaciones de los oxchuqueros sobre el ch'ulel-alma están más en consonancia con los postulados cristianos, la información recabada no es extensa. En la actualidad, además de que este constituye el «soplo de Dios», se dice que al momento de la concepción esta entidad se asienta en el cuerpo del nuevo ser «dándole apoyo y fuerza para que se desarrolle». Eso, desde una perspectiva religiosa, lleva a que los hijos sean considerados «regalo de Dios-Tatil».

Cuando la persona muere, el cuerpo va al panteón y el ch'ulel-alma, según su comportamiento, al cielo o al K'atin'bak 'infierno'. O de pasada por este último para expiar los pecados y luego al cielo (no se hace mención de la noción de Purgatorio).

En lo que toca a los tsotsiles, estos nos han nutrido con abundantes elementos sobre el parti-

\footnotetext{
${ }^{4}$ La palabra ch'ulel proviene del vocablo $c h$ 'ul 'sagrado'. El concepto que en la actualidad sostienen los mayas de los Altos de Chiapas es resultado de la presencia de elementos de origen prehispánico y cristiano. En dicho sentido la noción ch'ulel-alma permite resaltar los elementos propios de ambas procedencias presentes en la entidad. La noción que actualmente estructura esta entidad y sus diferencias entre los distintos pueblos de los Altos de Chiapas deriva de la entremezcla y resignificación de ambos elementos, dando como resultado una entidad que por un lado corresponde al «soplo de Dios», la presencia divina e inmortal en la persona, concepto esencialmente católico, y, por otra, desde una noción prehispánica, se constituye a la vez por sí misma en una diversidad de seres etéreos similares, es decir, varios ch'ulel o compartimentaciones de ch'ulel, ambos posibilidades presentes entre los tsotsiles de Chamula y Chenalhó (Page 2011: 172), lo cual como ya se señaló, tendrá diferente intensidad dependiendo del pueblo de que se trate, siendo esta siempre una entidad anímica con intencionalidad pero sin responsabilidad, ya que la responsabilidad reside en el corazón de la persona cuyo asiento es el cuerpo (Page 2010: 105).
}

cular. Predomina la opinión de que antes de que el ch'ulel-alma se asiente en el cuerpo tiene que recorrer un largo camino desde Yan-Vinajel 'morada celestial' hasta el cuerpo de la persona que le corresponde donde necesariamente se topa con el Pukuj 'Diablo', quien, dependiendo de la habilidad de que dicha entidad haya sido dotada por las deidades celestiales, le impondrá un número variable de vayijelitik 'animales compañeros' con diferente fuerza y poder sobrenatural (Page 2011). Esto de ninguna manera implica, según Arias (1975: 29), que desde ese momento al nonato se le considere persona, sino que el estado de persona se alcanza cuando se tiene «conciencia cabal ... nadie tiene un alma cabal hasta que pasa a ser lo que su sociedad considera un miembro completo de la comunidad». Lo cual sucede entre los 13 y los 18 años de edad o más tarde.

En relación con la trayectoria del ch'ulel-alma después de la muerte, en la década de 1960 se registraron varias versiones entre chamulas y pedranos: una es que inmediatamente después del deceso estos van a buscar otro dueño, alguna criatura aún en el vientre materno que aún carezca de este entidad. Los «niñitos» que yacen en el vientre materno sueñan que los ch'ulel-alma les hablan pidiéndoles que los reciban. Si el cuerpo difunto era de mujer, tiene que buscar hombre, o viceversa.

En Chenalhó Guiteras (1965: 241) reportó que cuando la persona muere el ch'ulel-alma va al segundo subestrato de entre cielo y tierra, ${ }^{5}$ donde pasa un tiempo equivalente al que estuvo en la tierra, sujeto a un proceso de involución hasta que todo vestigio de su vida anterior desaparece. Llegado a este punto, puede incorporarse a un cuerpo en gestación. Por lo mismo, no existe ningún tipo de liga entre las diferentes reencarnaciones de un ch'ulel-alma. Versión que

\footnotetext{
${ }^{5}$ La estructura del universo a que hacen referencia chamulas y pedranos se compone por tres estratos, a saber: tierra, entre cielo y tierra y cielo. En el estrato entre cielo y tierra tiene lugar una compartimentación que puede ir de nueve a 13 subestratos, cada uno con diferentes características: algunos de estos poblados por envidiosos enanos, otros con compartimentaciones del ch'ulel-alma, otros desiertos y los que son de acceso exclusivo a las deidades secundarias o celestiales.
} 
también fue recabada en las entrevistas realizadas en Chamula y Chenalhó para este trabajo.

En otra versión sobre el destino del ch'ulel-al$m a$, se apunta que al morir la persona, esta entidad se va al segundo estrato entre cielo y tierra, donde esperará junto con todos los ch'ulel-alma de los difuntos el día del juicio final. Por lo mismo, sin juicio final resulta obvio que aún no hay infierno, que es el sitio a donde la mayoría se irá, razón por la cual tampoco en el cielo se reciben abonados. Lo anterior deja fuera de consideración la posibilidad de reencarnación de esta entidad y se inclina favorablemente hacia los postulados cristianos.

Uno u otro destino dependerá del tipo de registros que hayan sido asentados en las distintas «listas» (Page 2010: 97) que llevan las deidades respecto de las buenas o malas acciones: «Bueno si tú crees en los dioses, pues te mandan por donde está el buen camino que es un lugar seguro para que el cuerpo descanse, pero si tu trabajo es tanto regaño, enojos o matar, pues te vas directo al k'atinbak 'infierno'» (entrevista a Marcos López Gómez, p. 34).

\section{CUERPO HUMANO}

Entre los mayas de los Altos de Chiapas que nos ocupan, las entidades anímicas perfilan los aspectos diferenciales a través de los que se va a delinear la corporeidad. El cuerpo, como me referiré en adelante al cuerpo humano, al decir de los colaboradores, constituye la entidad de la persona que durante la vigilia efectúa el contacto con la sociedad; contiene en el corazón el ch'ulel-alma, entidad anímica más importante de la persona por ser, como se señala más arriba: «el soplo de Dios». Dicha entidad «habla» con el j-ilol y el pik'abal o majtanil a través de la sangre. A excepción de quienes están dotados de la capacidad de transformarse, el resto de entidades anímicas que conforman la persona radican fuera del cuerpo en espacios de Yan Balamil 'otra tierra'.

${ }^{6}$ De entre los diferentes cuerpos con que se constituye la persona maya alteña de Chiapas, hago la distinción entre el cuerpo humano y el cuerpo animal correspondiente al vayijelil o animal compañero.
Si bien el vínculo entre las entidades que conforman a la persona en los distintos municipios es el ch'ulel-alma, es a través de los actos realizados en diferentes espacios y con diferente responsabilidad - religiosos, cargos, vida cotidiana, etc.- - que la persona ejecuta por intermedio del cuerpo lo que principalmente coadyuva a la protección o perjuicio de esta y del resto de las entidades anímicas.

Cabe señalar además que si bien todas las entidades anímicas poseen volición, no tienen discernimiento sobre la responsabilidad de sus actos. Es en la entidad cuerpo donde reside la conciencia y responsabilidad sobre estas.

El cuerpo es el único medio para dar cumplimiento al mandato primordial de adorar y sostener a las deidades celestiales, lo que tiene por objeto, entre otras cosas, contener las acciones que sus contrapartes emprendan, las cuales, de llevarse a cabo, generalmente las ponen en peligro, lo que repercutirá en sufrimiento corporal. Destaca, por ejemplo, la gulosidad del ch'ulel-al$m a$, que lo expone a empachos y envenenamientos, además de su proclividad a exponerse en espacios del Yan Vinajel-Yan Balamil 'otro cielo-otra tierra' donde puede ser golpeado, secuestrado o devorado.

Por otro lado, respecto de los vayijelil 'animales compañeros' existe el riesgo, por falta de empeño en el cumplimiento del mandato primordial, de que sean expulsados del corral que guardan los anjeletik vaqueros, lo que los expone, si se trata de predadores, a ser aniquilados por los campesinos que se ven afectados por la mortandad que llegan a causar entre sus animales domésticos; y si de roedores o aves que no sean de presa, a ser devorados por algún predador (Page 2010).

Asimismo, se considera que a través de ciertas expresiones corporales y rasgos físicos, es posible vislumbrar la debilidad o fortaleza física, emocional y espiritual de la que una persona está dotada, lo cual de alguna manera determinará los roles sociales, laborales y religiosos que a lo largo de la vida la persona lleve a cabo.

El cuerpo «proporciona un rostro» (Le Breton 2006: 7). Atendiendo a esta cita y como señalo en otro trabajo (Page 2011), el cuerpo humano de los tsotsiles y tseltales que nos ocu- 
pan destaca en el marco de la persona como la entidad en que reside la percepción inmediata y mediata del mundo y la conciencia. Y como señala López-Austin (1996: 171-172), desde la perspectiva del «complejo religioso mesoamericano», en el cuerpo reside el principio organizador de las relaciones sociales, y es a partir de este que se definen los aspectos fundamentales de la cosmovisión, las taxonomías a través de las que se entiende y se nombra la naturaleza; por lo que, concomitantemente, aglutina y organiza las entidades anímicas que conforman la persona.

En este sentido, pero sobre todo porque entre los mayas que nos ocupan el cuerpo es asiento del ch'ulel-alma y en este reside la conciencia, se ubica dentro del complejo persona como responsable de la persona ante las deidades y la sociedad y sobre este repercuten todas las acciones que las entidades anímicas lleven a cabo, sin por ello tener mayor importancia que cualquiera de estas.

Cabe señalar que la compartimentación que hacemos de las entidades tiene un carácter estrictamente analítico, ya que entre los colaboradores de uno y otro municipio la noción de cuerpo no es simbolizada ni experimentada como una entidad individualizada, demarcable entre lo sobrenatural y lo social.

Veamos ahora cómo se hace referencia al cuerpo. Hemos documentado que entre los católicos actuales de Oxchuc se dice que Dios creó al primer hombre de barro y lo animó por medio del soplo divino, con lo que el barro se transformó en "carne, huesos, venas y sangre», también en órganos como el chinam 'cerebro', para poder grabar lo que se ve en el mundo.

por fuera del cuerpo tenemos las siguientes partes: dos manos para agarrar toda clase de cosas y para trabajar; dos ojos para ver el mundo y distinguir todo lo que hay a nuestro alrededor; los pies o patas para caminar y para sostener todo el cuerpo y, también la carne que tenemos cubierta con pantalones y camisas para protegerlo.

\section{Ahora, lo que tenemos adentro del cuerpo:}

pues, primero, es nuestra vida, o sea la sangre que circula por las venas y entre los músculos hasta que llega al corazón donde tiene fuerza para respirar y latir con normalidad para vivir; luego están los órganos, como intestinos o tripas donde se guarda el alimento; los riñones; los pulmones que nos ayudan para respirar; la boca y la lengua para hablar; oídos para escuchar y otros más, nomás que ya no sé cómo se llaman. Por otra parte, allí está nuestro cerebro que trabaja junto con nuestra mente. Eso es todo lo que tenemos para vivir en el mundo (entrevista a Faustino López, p. 10).

En otro testimonio se nos dijo:

Bueno, adentro está lo principal para la vida que es el corazón, allí está el lugar para nuestra comida, como la tripas o intestinos, ya que nosotros no tenemos tzukum ['panza'] como los animales, nosotros solo tenemos unos intestinos grandes donde se guarda la comida. También tenemos los riñones, los sejk'ub, pulmones, la sangre que circula en todo el cuerpo, y las venas por donde corre nuestra sangre grande para alimentar toda la carne. Eso es lo que tenemos adentro.

Ahora, lo que tenemos afuera del cuerpo, primero son nuestras piernas y pies que nos sirven para caminar por todas partes, los brazos y manos que nos sirven para movernos y trabajar en el campo, la cabeza y cerebro que nos sirve para pensar y grabar todo lo que nos dicen, también allí está la mente que nos sirve mucho para memorizar el estudio. Bueno, en la misma cabeza están nuestros ojos, las orejas que nos sirven para mirar y distinguir a las personas o cualquier cosa y escuchar lo que dice o leer; también allí está la nariz con que podemos olfatear cualquier olor como el que despide la comida que comemos con la boca. La boca nos sirve para comer y para hablar; tenemos la voz con sonido pero es por la lengua que tenemos, ya que la lengua se mueve al hablar, por eso sale el sonido, si no fuera por la lengua no podríamos hablar, hacer contacto con la otra gente, por eso es muy importante que tengamos lengua, boca, oído y nariz, eso es lo que tenemos todo en afuera (entrevista a Florentina López, p. 16).

La carne, que está pegada a los huesos por todo el cuerpo, está sostenida por estos, pero la fuerza viene de la sangre, que es impulsada por el corazón que, de los fluidos y los órganos son los de mayor importancia por su doble acepción corpórea y sutil, claramente expresada en el fragmento testimonial antes presentado («es nuestra vida, o sea la sangre que circula por las venas y entre los músculos hasta que llega al co- 
razón donde tiene fuerza para respirar y latir con normalidad para vivir»).

La sangre, circula por dos tipos de «venas», por una, sangre roja y, por la otra, sangre «medio verde». La sangre se nutre del alimento que se le provee al cuerpo.

Tanto entre tseltales como entre tsotsiles la sangre constituye el vehículo, «la sangre habla» a través de la pulsación que realiza, entre los tsotsiles el j-ilol y entre los tseltales el pik'abal o majtanil, el ch'ulel-alma y las deidades comunican los infortunios, peligros y enfermedades que acaecen a la persona y la manera en que las diferentes entidades están involucradas, y las características específicas de las acciones rituales y los procedimientos curativos encaminados a «ayudar a sanar» a las personas con los problemas detectados.

Bueno pues como yo soy jilol lo que hago es pulsar, es tocar tu pulso, entonces allí se dice, allí se puede sentir si viene de frío o de calor o si ha hecho algo en las cuevas, en los ríos, en fuego. Allí se puede mencionar así que no podemos inventar y no podemos saber sino que solo en el pulso, porque solo verlo en la cara no se ve nada, tenemos que pulsarlo, verlo cual es la enfermedad de cada uno, de dónde viene y si el diablo le hace daño, o quién. Si es envidia, si es hombre, si es mujer allí se siente en el pulso, entonces no me puede mencionar o decir que no se siente, allí se siente todo. Y cómo se siente, si se necesita rezar tenemos que rezar y se siente también si sólo vamos a poder usar plantas, si le voy a dar plantas a los enfermos, a los niños, a las niñas. Todo allí se siente; si se puede calmar con plantas y si no pues también necesita que se cure, necesita que rece, que le haga todo de acuerdo como se siente en el pulso porque allí dice también si quiere rezada o si quiere j-ilol allí se siente (entrevista a don Antonio Vázquez, p. 32).

\section{CONSIDERACIONES FINALES}

En síntesis, respecto de las posturas de ambas etnias, todas las descripciones del cuerpo que los oxchuqueros nos proporcionaron están matizadas por las funciones físicas que este tiene, predominantemente las ligadas al trabajo, en tanto que las referencias a los órganos se centran en el corazón on'ton por considerársele, como ya se señaló, asiento del ch'ulel-alma e impulsor de la sangre, elemento que a su vez no solo es considerado corporal sino vehículo de la divinidad y morada de las entidades anímicas y el cerebro como asiento de la memoria, el aprendizaje y el saber.

Notamos, por otro lado, que entre los jóvenes oxchuqueros prevalece una visión dualista en la que la persona se concibe como cuerpo y alma. Ello debido a la fuerte influencia en el municipio de la educación primaria y secundaria y de grupos cristianos protestantes y católicos.

Por lo que toca a los tsotsiles de Chamula y Chenalhó, nos hemos topado con una noción de corporeidad en cuya subjetividad y prácticas sociales y religiosas se reflejan dinámicas en las que este y las entidades anímicas conforman un conglomerado único, donde el cuerpo opera como enlace con la familia y la sociedad, y se constituye, por lo mismo, como centro de la acción social y religiosa, receptor y portador del éxito y el infortunio en todos los sentidos - físico (salud-enfermedad-muerte), social, emocional, intelectual y espiritual, y como entidad responsable del conjunto de la persona ante los hombres y las deidades.

$\mathrm{Al}$ respecto don Antonio Vázquez (entrevista, p. 86) nos dijo: «Encima del cuerpo no es tan fácil que se enferme, no es tan fácil que se hinche, que le pase algo porque lo está protegiendo la piel y eso ayuda. Dios nos mandó con la piel para aguantar los golpes, el calor, el frío. Pero adentro es donde hay peligro».

Entre chamulas y pedranos tradicionalistas llama la atención el hecho de que a pesar de que el cuerpo actúa como concreción material de la persona, en la práctica se han interesado poco por su estructura y funciones, ${ }^{7}$ toda vez que el trinomio salud-enfermedad-atención está condicionado principalmente por las consecuencias a favor o en contra que resultan del cumplimiento del mandato primordial de adorar, nutrir y sostener a las deidades. La concreción material de esto se constata en el proceso de trabajo de los j-loletik los que pueden ver y escuchar) en que el único contacto físico que establecen con el

${ }^{7}$ Según refirió Holland (1963: 155), para los tsotsiles de San Andrés, el cuerpo estaba simplemente compuesto de huesos y carne, sin dar mayor importancia a vísceras y órganos. 
enfermo es para buscar los pulsos en diferentes partes de cuerpo con objeto de consultar la palabra que el ch'ulel-alma y las deidades emiten a través de la sangre.

Así es, yo no puedo mirarlo en la cara nada más porque en eso no me doy cuenta que es lo que tiene, entonces es lo que hago yo, no puedo verlo nada más en la cara, yo no soy como los doctores, los doctores te abren los ojos, abren la boca y te tocan la panza. Pero eso que vamos a saber, ¿qué es lo que tiene?, ¿si es frío o caliente la enfermedad? A fuerza se siente cuando se pulsa al enfermo. Así lo pulso. Yo por medio del pulso lo veo, voy a conocer cualquier enfermedad no hay otras cosas, no puedo hacer otras cosas es lo que único que se puede hacer. Así lo hago en todo, así lo encuentro las enfermedades por medio del pulso, de donde viniera, de donde quiera que vinieran los enfermos que sean Kashlantik [ladinos], que sean indios, que sean chamulas, que sean de Chalchihuitán, que sean de Pantelhó vienen de otros lugares y si por medio del pulso, no hay otras cosas como se puede notar, como se puede dar cuenta que enfermedad tiene cada quien (entrevista a don Antonio Vázquez, p. 33).

Ciertamente los tsotsiles participantes identifican la mayor parte de órganos y vísceras que conforman parte del cuerpo. Sin embargo, en términos de salud y enfermedad solo hacen mención reiterada del corazón por ser considerado asiento del ch'ulel-alma y expresión de las emociones, la sangre como vehículo de comunicación del mundo sagrado y el cerebro como recinto de la memoria y productor de pensamientos. $^{8}$

Décadas atrás, como documentó Guiteras (1965: 247), entre los pedranos se pensaba que el corazón era el asiento de la memoria y el conocimiento, y a través de este se sentía. En la actualidad, se considera que en el cerebro se

\footnotetext{
${ }^{8}$ López-Austin (1996: 199) señala: «la creencia en los centros y en las entidades anímicas se debe en parte a una necesidad de explicación de funciones muy complejas, mismas que las sociedades antiguas fueron relacionando con alteraciones fisiológicas reales, las que les producían la certeza de la existencia de centros anímicos, orgánicos, rectores de dichas funciones. Puede señalarse como ejemplo muy simple el vínculo que el hombre descubre entre sus pasiones amorosas y las palpitaciones del corazón. De la sensación y de la relación conceptual primaria podría generalizarse a otras relaciones, ya puramente imaginarias».
}

asientan las funciones mentales y de memoria, pero en el corazón prevalece la sabiduría y el discernimiento. Fuera de estos dos órganos, es mínima la referencia a otros.

El elemento más importante de incorporación judeo-cristiano es la consideración de que el ch'ulel-alma constituye el soplo divino, la vida misma; sin embargo, este no provee al cuerpo de fuerza, sino que esta es provista por Dios de manera independiente, mandando que se restablezca mediante el consumo del maíz, demás alimentos y el descanso.

Dios manda los huesos y «las cuerdas» para poder caminar; manda la sangre y en ella el color de la piel, en ella reside el poder y por ahí entra la enfermedad en el cuerpo y produce, en consecuencia, debilidad; entonces, la piel se pone muy amarilla o muy negra.

Si bien el bienestar o malestar de la persona no está referido exclusivamente al cuerpo, este viene a ser el punto, el espacio de concreción y de referencia en términos de salud-enfermedad, armonía o desarmonía causadas por el deambular constante de las entidades anímicas. Por ello, en él reside la esperanza de vida, la longevidad.

Hay varias enfermedades que vienen de ese mal echado, traen cansancio, dolor de huesos, dolor de cuerpo, dolor de la cabeza, se siente muy feo, muy revuelto vienen las enfermedades así que allí lo sentimos, allí lo probamos solo con pulso, ninguna otra cosa, esa es nuestra forma (entrevista a don Antonio, p. 31).

También el cuerpo se sitúa como elemento mortal de la persona, ya que luego de su deceso se disuelve el vínculo entre las entidades anímicas de las cuales, entre los tsotsiles, los animales compañeros también mueren, mientras que al ch'ulel-alma le acontece lo arriba narrado.

Un atributo que destaca en el discernimiento materia-espíritu es lo apestoso que para las deidades resulta el cuerpo de las personas, mismo que las deidades celestiales no soportan y constituyó la causa por la que no quisieron vivir sobre la faz de la tierra, migrando al cielo u espacios alejados de la humanidad sin permitírseles al acceso a estos. Ello apunta a situar, como establece la noción cristiana, al cuerpo como el aspecto deleznable, asiento del pecado y las pasiones 
malsanas de la persona, pero también a la falta de higiene. Por otro lado, se refiere al trato que hasta poco recibían tsotsiles y tseltales por parte de españoles y mestizos que, aduciendo dichas razones, no les permitían, entre otras cosas, el acceso a sus casas o edificios públicos.

Así, entre los tsotsiles y tseltales que han participado en la investigación, nos topamos con dos nociones de persona, por un lado la proveniente de su cultura ancestral con abundantes elementos tanto prehispánicos como judeo-cristianos, lo que coadyuva, por ejemplo, a utilizar la designación ch'ulel-alma, más arriba señalada, por contener elementos de ambas tradiciones, de donde provienen también las nociones de animal compañero y la capacidad de transformación o de imponer la voluntad sobre estos fenómenos naturales del panteón prehispánico. La consustancial subjetividad de la noción de persona se constata en el cotidiano vivir, en la excepcionalidad de la enfermedad y la muerte y en la coherencia entre sus concepciones y los procesos para ayudar a mantener la salud o sanar de las enfermedades. Al respecto Le Breton (2006: 8), luego de sus observaciones en otros ámbitos, ha concluido «que el cuerpo no se distingue de la persona».

Por otro lado, sobre todo entre los jóvenes de ambas etnias prevalece la visión de la sociedad dominante desde la que predominantemente se ha impuesto la visión judeo-cristiana de persona conformada por cuerpo-alma, contrapuesta a la de aquellos que ya no se adscriben a religión alguna y que tienen una visión materialista del cuerpo solo.

No se nace siendo persona sino que el individuo se constituye como tal, como señala Pérez (1991: 14), a través de la educación, el implante de «un conjunto de actos eficaces tradicionales», técnicas corporales, emocionales y espirituales que son «un montaje físico-sociológico», mediante los cuales la sociedad educa para construir con ello la noción de persona y de ese modo adaptar al sujeto a su entorno social inmediato, y llevarlo con ello a conformar no solo una visión de sí, del conjunto social en el que está inmersa y de los otros, sino también una forma de vivirse, enfermarse, padecer y morir.

\section{FUENTES DE CONSULTA}

Arias, Jacinto, 1975, El mundo numinoso de los mayas: estructura y cambios contemporáneos, Tuxtla Gutiérrez, Instituto Chiapaneco de Cultura.

Bartolomé, Miguel, 1991, «La construcción de la persona en las etnias mesoamericanas», en Anuario del Centro de Estudios Superiores de México y Centroamérica, Chiapas, UNICACH/ Gobierno del estado de Chiapas.

Diesmo, Antolín, 2012, «Los significados del o'nton desde la mirada de un jchanvun "estudiante" tsotsil», tesis de maestría inédita, San Cristóbal de Las Casas, cIEsAs-Sureste.

Favre, Henri, 1973, Cambio y continuidad entre los Mayas de México: contribución al estudio de la situación colonial en América latin, México, Siglo XXI Editores.

Gossen H., Gary, 1975, «Animal souls and human destiny in Chamula», Man (N. S.), v. 10, pp. 448-461.

Guiteras Holmes, Calixta, 1965, Los peligros del alma, México, FCE.

Harman, Robert C., 1990 [1974], Cambios médicos y sociales de una comunidad maya-tseltal, México, INI/Conaculta.

Hermitte, M. Esther, 1970, Poder sobrenatural y control social en un pueblo maya contemporáneo, Chiapas, Consejo Estatal de Fomento a la Investigación y la Difusión de la Cultura, (Cuadernos Municipales).

Holland, R. William, 1963, Medicina maya en los Altos de Chiapas: Un estudio del cambio socio-cultural, México, INI.

Köhler, Urlich, 1995, Chonbilal ch'ulelal-alma vendida. Elementos fundamentales de la cosmología y religión mesoamericanas en una canto maya-tzotzil, México, IIA-UnAm.

Le Breton, David, 2006, Antropología del cuerpo y modernidad, Buenos Aires, Ediciones Nueva Visión.

López-Austin, Alfredo, 1992, Los mitos del tlacuache, México, Alianza Editorial. 
López-Austin, Alfredo, 1996, Cuerpo humano e ideología: Las concepciones de los antiguos nahuas, México, unAm (Serie Antropológica: 39).

López Hernández, Juana, 2007, «La práctica médica tradicional y sus representaciones en los problemas de salud que ocasionan la muerte materna en San Juan Chamula», tesis de licenciatura inédita, México, UNACH.

Lupo, Alessandro, 1999, "Nahualismo y tonalismo», en Arqueología Mexicana, 6(35), pp. 16-23.

Meslin, Michel, 1978, Aproximación a una ciencia de las religiones, Madrid, Ediciones Cristiandad.

Moguel V., Reyna y Manuel R. Parra, 1998, «Los ladinos rurales de Huixtán y Oxchuc: un caso de involución social», en M. E. Reyes Ramos, R. Moguel Viveros y G. van del Haar (coords.), Espacios disputados: transformaciones rurales en Chiapas, México, UAM-X/Ecosur/WAU/CEDLA.

Page Pliego, Jaime, 2010, Yombil "Puesta su flor en el altar". Una mirada a la etnomedicina en Oxchuc, Chiapas a partir de los j-poxtawanejetik organizados, México, Proimmse-IIA-UnAM.
Page Pliego, Jaime, 2011, El mandato de los dioses: Medicina entre los tsotsiles de Chamula y Chenalhó, Chiapas, $1^{\mathrm{a}}$ ed. digital, San Cristóbal de Las Casas, Proimmse-IIA-UnAm.

Pérez Cortés, Sergio, 1991, «El individuo su cuerpo y la comunidad», Alteridades, I(2), pp. 13- 23.

Pitarch, Pedro, 1996, Ch'ulel: Una etnografía de las almas tzeltales, México, FCE.

Pozas Arciniega, Ricardo, 1977, Chamula, México, INI (Clásicos de la Antropología Mexicana).

Sánchez Carrillo, Oscar, 2007, «Cuerpo, ch'ulely lab. Elementos de configuración de la persona tzeltal en Yajalón, Chiapas», en Pueblos y fronteras digital, Proimmse-IIA-Unam, n. 4, en www.pueblosyfronteras.unam.mx [consulta: 23 de febrero de 2008].

Siverts, Henning, 1969, Oxchuc: una tribu maya de México, México, Instituto Indigenista Interamericano.

Villa Rojas, Alfonso, 1990, Etnografía tseltal de Chiapas. Modalidades de una cosmovisión prehispánica, Chiapas, Consejo Estatal para el Fomento de la Investigación y Difusión de la Cultura-Gobierno del estado de Chiapas. Vogt Z., Evon, 1980, Los zinacantecos, Méxio, INI.

Fecha de recepción: 15 de agosto de 2013

Fecha de aceptación: 11 de septiembre de 2014 